\title{
Modeling the Water Sorption Isotherms of Warionia Saharae and determination of sorption heats and drying kinetics
}

\author{
Fedol, A. ${ }^{a^{*}}$; Cheriti, A. ${ }^{\text {a }}$
}

a* Faculty of Medicine, Facmed-univ-oran1,Oran ,31000,Algeria

a* Department of Chemistry, Kasdi Merbah University , Ouargla, 30000, Algeria

a Phytochemistry \& Organic Synthesis Laboratory, Faculty of Medicine, UTMB, Bechar, 08000, Algeria.

*E-mail of the corresponding author: amelfedol@yahoo.fr

\begin{abstract}
The hygroscopic equilibrium of Warionia saharae was studied, which allowed getting an idea of the equilibrium water content relative to a given humidity. The results of this study made it possible to have the sorption curves. The results of this study made it possible to obtain the sorption curves necessary for know the storage conditions of the plant and the study of its drying kinetics. The static gravimetric method was used to determine sorption isotherms of Warionia saharae leaves at 30and $40{ }^{\circ} \mathrm{C}$ and in the range of water activity varying from 0.063 to 0.898 . The Gab, Peleg models was found to be the most suitable for describing the sorption curves. The isosteric heat calculated by applying the Clausius-Clapeyron equation .The desorption isosteric heat was higher than the isosteric heat of adsorption and both decreased continuously with increasing of the equilibrium moisture content. The experimental results obtained allowed us to determine the temporal evolution of the drying kinetics as a function of the moisture content. The curve of the evolution of the water content as a function of time shows the absence of the phases product temperature and constant drying rate
\end{abstract}

Keywords: Sorption isotherm, isosteric heats, modelling, kinetics, Warionia saharae. 
Modeling the Water Sorption Isotherms of Warionia Saharaeand determination of sorption heats and drying kinetics

\section{Introduction}

The Warionia saharae, which belongs to the important composite's family, is an endemic species of North Africa, characterized by a discerning odour [1]. The leaves of Warionia saharae are used in traditional medicine to treat inflammatory diseases, gastrointestinal disorders and against epileptic crisis [2,3]. Crude extracts of this plant showed antiinflammatory and cytotoxic activities against a cancer cell line (KB cells) [4,5]. The methanolic soluble fraction of the dichloromethane extract of Warionia saharae afforded cytotoxic and anti-inflammatory sesquiterpene lactones [3-6], while hexanoic extract showed the presence of several hydrocar bon acid derivatives [7].Like many other herbs, is highly seasonal in nature. In order to preserve this seasonal and highly perishable plant and make them available to consumers all year round at low prices, it is subjected to post harvest technological treatments [8].Several process technologies have been employed on an industrial scale to preserve food products; the major ones are canning, freezing, and dehydration. Among these, drying is especially suited for developing countries with poorly established low-temperature and thermal processing facilities. It offers a highly effective and practical means of preservation to reduce postharvest losses and offset the shortages in supply. Drying is a simple process of moisture removal from a product in order to reach the desired moisture content and is an energy intensive operation. The prime objective of drying apart from extended storage life can also be quality enhancement, ease of handling, further processing and sanitation and is probably the oldest method of food preservation practiced by humankind [9].In the literature several methods are mentioned to analyze the drying of hygroscopic products (theoretical, empirical and semiempirical).The empirical models of drying show a direct relationship between average moisture content and drying time.

\section{Materials and Methods}

The leaves of Warionia saharae, used for the drying experiments were collected from the region of southwest Algeria (Jebel Anter, wilaya of Bechar). In the period of May 2012.The moisture content was measured and the equilibrium moisture contents of Warionia were determined at temperatures of 30 and $40 \circ \mathrm{C}$ over a water activity range of $0.063-0.89$ using the static gravimetric method. For prevent destroy plant chemical components like essential oils, the leaves of Warionia saharae, were drying in shade.

\subsection{Equilibrium moisture content determination}

The desorption equilibrium moisture contents of Warionia saharae leaves were determined at temperatures of 30 and $40{ }^{\circ} \mathrm{C}$ over using the static gravimetric method. This method 
involves the use of saturated salt solutions to maintain constant relative humidity (aw) in enclosed still moist air at a certain temperature to obtain the complete sorption isotherms. The mass transfer between the product and the ambient atmosphere was assured by natural diffusion of the water vapor and the water activity of the product equals the relative humidity of the atmosphere at equilibrium conditions. Seven saturated salt solutions $(\mathrm{KOH}$, $\mathrm{KF}$, K2CO3, NaNO3, $\mathrm{NaCl}, \mathrm{KCl}$ and $\mathrm{BaCl} 2)$.

\section{Modeling of the drying curves}

Four models were used to describe the sorption isotherms (table.1). The goodness of fit for each model can be evaluated based on the relative percent error $(\mathrm{P})$, which compares the absolute difference between the predicted moisture contents with the experimental moisture contents. Relative percent errors values lower than $10 \%$ indicate a good fit [11].

Table 1 .Mathematical models applied to drying curve

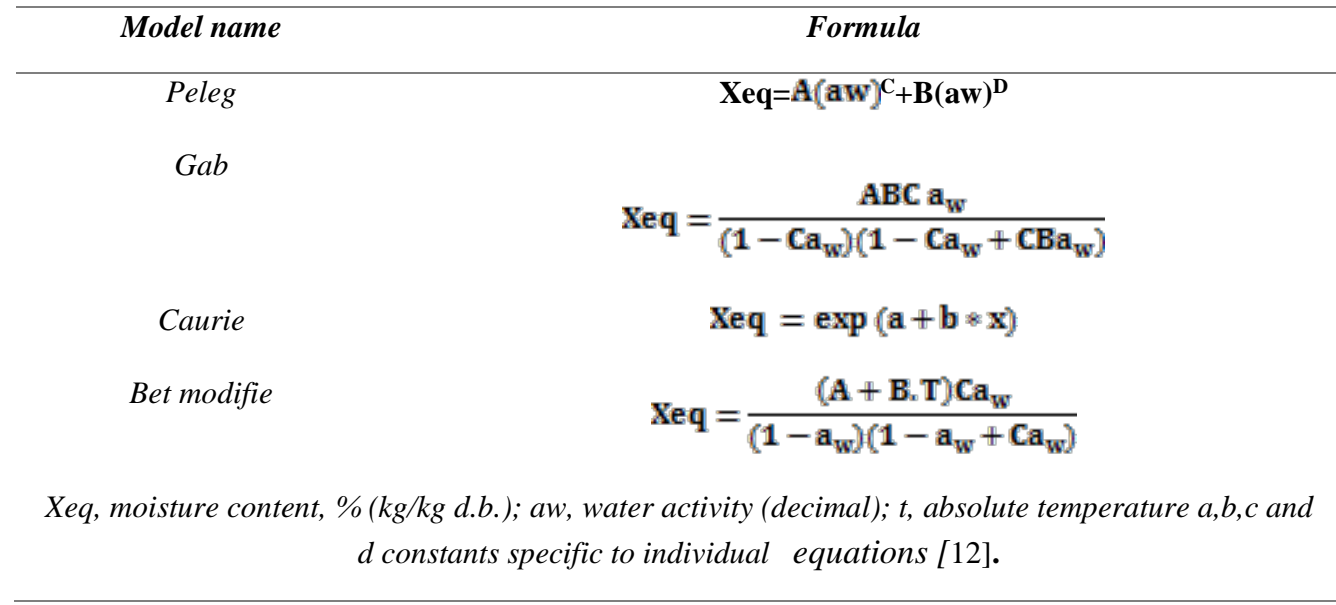

\section{Result and discussion}

\subsection{Sorption isotherms}

In this study, models were used in predicting the sorption isotherms of Warionia leaves. Based on the statistical analysis, average relative error and standard error estimation were used to select the best model describing the shade drying curves of Warionia saharae leaves. Peleg and Gab models has a correlation coefficient value of 0.998, which is higher than Bet and Caurie. This means that Peleg and Gab models are the most suitable models for describing the relation between equilibrium moisture content and water activity. It was observed also that the moisture content decreases with time and drying rate increases with increasing temperature. 
Modeling the Water Sorption Isotherms of Warionia Saharaeand determination of sorption heats and drying kinetics

Table 2. Modeling parameters of Warionia Saharea

\begin{tabular}{|c|c|c|c|c|c|c|c|c|c|}
\hline \multirow{2}{*}{ 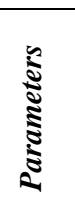 } & \multirow{2}{*}{${ }^{T} \mathrm{C}$} & \multicolumn{4}{|c|}{$\begin{array}{l}\text { Table 2.a. Estimated parameters of the different } \\
\text { models fitted to the desorption data }\end{array}$} & \multicolumn{4}{|c|}{$\begin{array}{l}\text { Table2.b.Estimated parameters of the } \\
\text { different models fitted to the adsorption }\end{array}$} \\
\hline & & Peleg & Gab & Caurie & Bet modifie & Peleg & Gab & Caurie & $\begin{array}{c}\text { Bet } \\
\text { modifie }\end{array}$ \\
\hline \multirow[t]{2}{*}{$\mathbf{A}$} & 30 & 1.880 & 0.085 & -5.119 & -0.015 & 0.122 & 0.085 & -4.940 & $-1.50 \mathrm{E}+2$ \\
\hline & 40 & 1.666 & 0.070 & -6.003 & -0.015 & 0.833 & 0.063 & -4.663 & $-1.55 E+2$ \\
\hline \multirow[t]{2}{*}{ B } & 30 & 0,101 & 0.0143 & 5.510 & 0.498 & 0.205 & 19.59 & -5.133 & 0.498 \\
\hline & 40 & 8.073 & $2.5 \mathrm{E}+001$ & 6.453 & 0.498 & 6.186 & 31.74 & 4.425 & 0.4 .984 \\
\hline \multirow[t]{2}{*}{ C } & 30 & 0.2706 & 1.004 & - & 8.115 & 1.325 & 0.986 & - & $4.10 \mathrm{E}+1$ \\
\hline & 40 & 0.144 & 1.024 & - & 3.402 & 0.104 & 0.982 & - & $7.81 \mathrm{E}+1$ \\
\hline \multirow[t]{2}{*}{ D } & 30 & 0.5380 & - & - & - & 6.650 & - & - & - \\
\hline & 40 & 0.3669 & - & - & - & 0.243 & - & - & - \\
\hline \multirow[t]{2}{*}{$\mathbf{r}$} & 30 & 0.996 & 0.998 & 0.968 & 0.998 & 0,988 & 0,992 & 0.979 & 0,989 \\
\hline & 40 & 0.998 & 0.997 & 0.983 & 0.994 & 0.987 & 0.980 & 0.966 & 0.978 \\
\hline \multirow{2}{*}{$\begin{array}{l}\mathbf{P}(\% \\
)\end{array}$} & 30 & 8.605 & 3,622 & 38.085 & 3.616 & 17,220 & 13,945 & 44,728 & 14,922 \\
\hline & 40 & 3.044 & 8.204 & 36.856 & 19.731 & 10,227 & 10,620 & 31.183 & 12.362 \\
\hline \multirow[t]{2}{*}{ SEE } & 30 & 0,005 & 0,002 & 0,037 & 0,001 & 0,030 & 0,034 & 0,006 & 0,047 \\
\hline & 40 & 0.001 & 0.001 & 0.032 & 0.005 & 0,001 & 0.001 & 0.019 & 0.002 \\
\hline
\end{tabular}

$P$ is average relative error (Eq. 1); SEE: is standard error estimation (Eq. 2); $r$ is correlation coefficient; $A, B, C$, Dare parameters of the equations; $T$ is temperature $\left({ }^{\circ} \mathrm{C}\right)$.

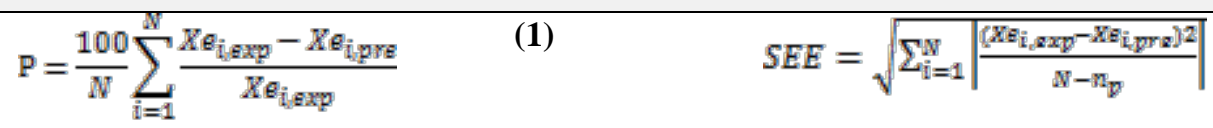

\subsection{Net isosteric heat of sorption}

The isosteric heat of sorption, were calculated from the equilibrium data at different temperatures using The Clausius -Clapyron equation .The curve shows that the heat of desorption decreased with increase in moisture content. The decrease in the isosteric heat with the increase in sorbed water content may be attributed to the fact that sorption initially occurs on the most active sites such as hydrophilic polar groups giving rise to the greatest interaction energy. With increase in the moisture content, as these sites become occupied, sorption occurs on the less active sites viz., peptide bonds or hydrophobic hydration sites resulting in lower heats of sorption $[13,14]$.The heat of desorption is greater than that of 
adsorption at low moisture contents for all the samples studied. This indicates that energy required in the desorption process is greater than that in the adsorption process [15]. The isosteric heats of desorption and adsorption of water in Warionia saharae leaves can be expressed mathematically as a power function of moisture content(3and 4):

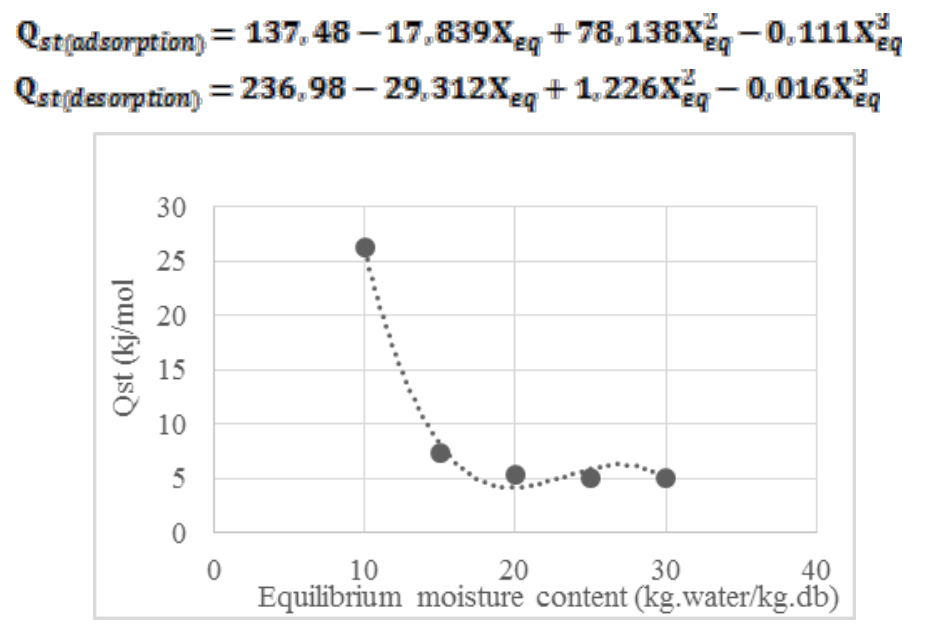

Fig.1 Adsorption isosteric heat

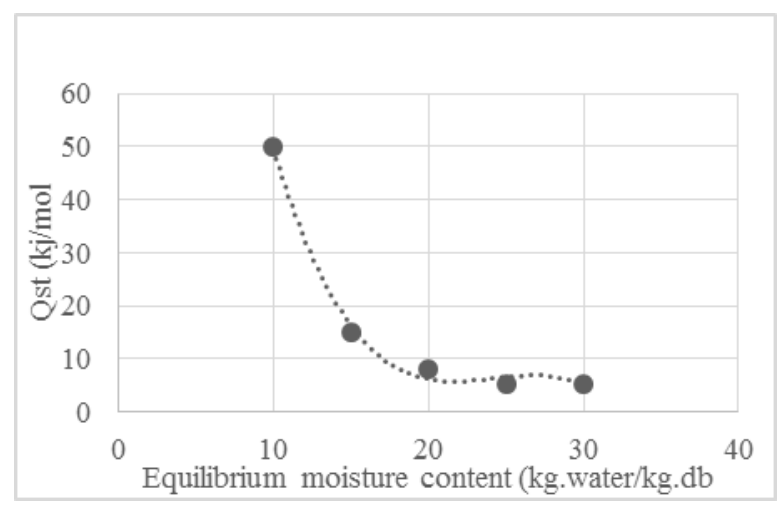

Fig .2 Desorption isosteric heat

\subsection{Drying rate:}

As seen in figure 5 the drying rate decrease rapidly in the first period of drying and slowly as drying progresses. The constant rate period is absent in the drying curves of Warionia saharae. Similar results were obtained for all agricultures and medicinal products [16]. These results can be explained by diffusion phenomena in the solid. This is a complex mechanism involving water in both liquid and vapour states, which is very often characterised by a so-called "effective diffusivity" [17].

The dimensionless drying rate was determined by the relation (3) : 
Modeling the Water Sorption Isotherms of Warionia Saharaeand determination of sorption heats and drying kinetics

$$
f=\frac{-\left(\frac{d x}{d t}\right)_{t}}{\left(\frac{d x}{d t}\right)_{0}}
$$

Where $\left(\frac{d x}{d t}\right)_{0}$, the initial drying rate .

The figure 3and 4 illustrate de variation of moisture ratio as a function of drying time. It is clear from these figures that the moisture content has an exponential decrease; it decreases continuously with the drying time.To determine the ratios of moisture during drying we used the following expression (4):

$$
X^{*}=\frac{X(t)-X e q}{X 1-X e q}
$$

Where

$\mathrm{X}^{*}$ : moisture ratio; $\mathrm{X}(\mathrm{t})$ : water content of product (\% d.b.); $\mathrm{X}_{\mathrm{i}}$ : initial water content of the product (\% d.b.); Xeq : equilibrium water content of the product (\%d.b.).

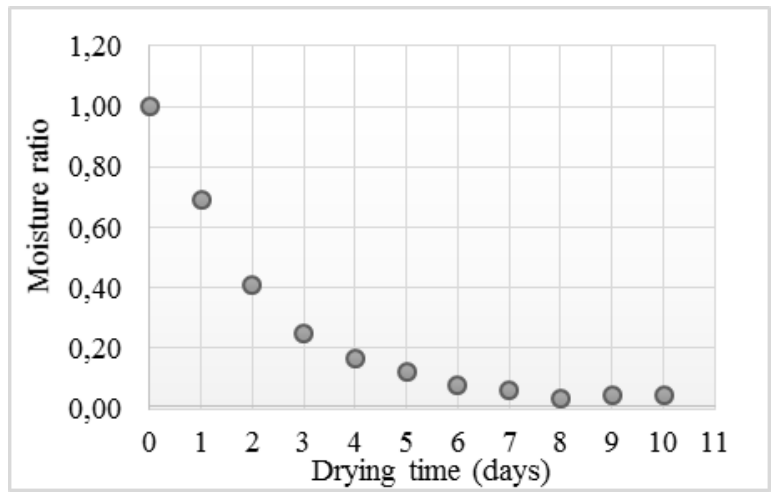

Fig. 3 moisture ratio as a function of drying time

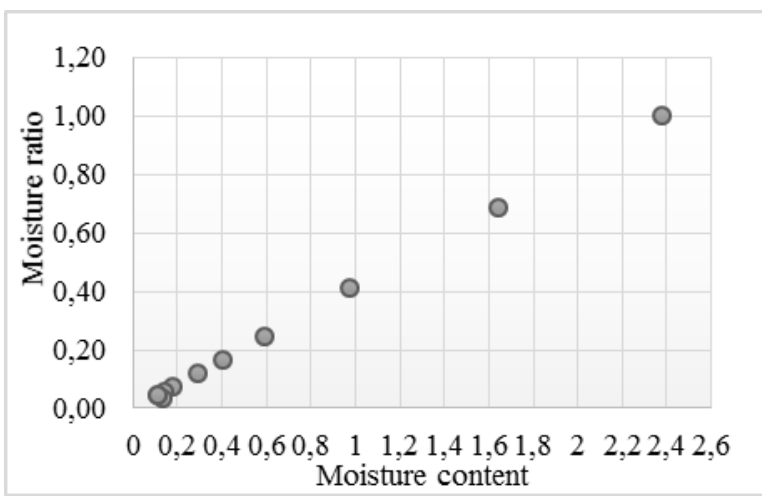

Fig .4 moisture ratio as a function of moisture content 


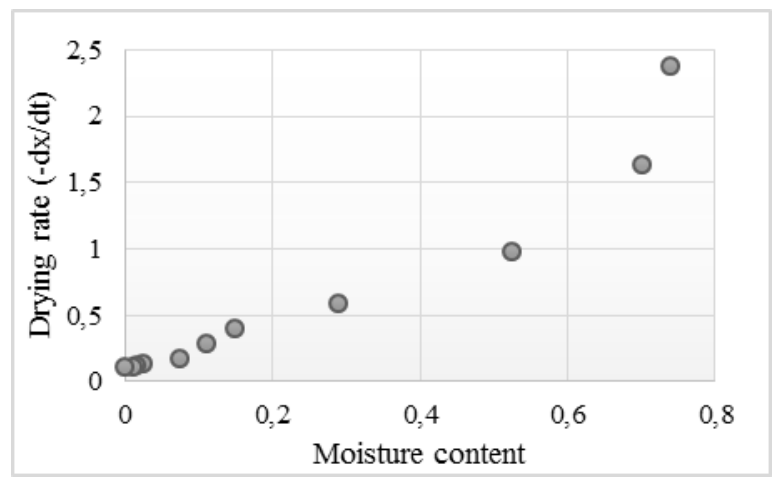

Fig.5 Drying rate as a function of drying time

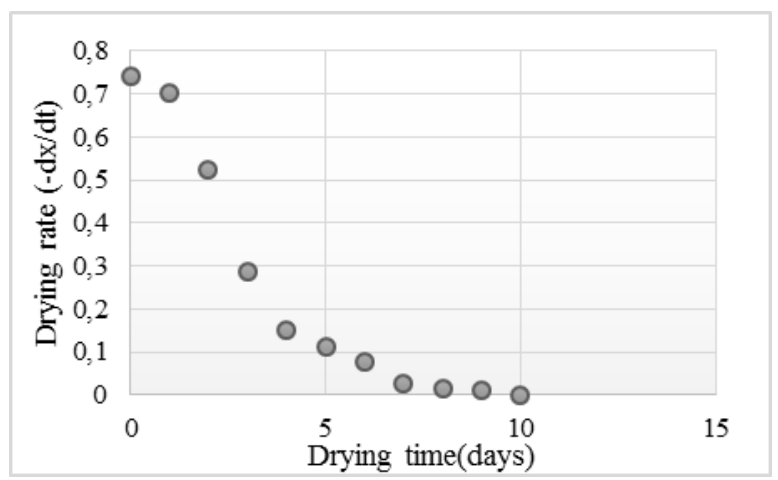

Fig.6 Drying rate as a function of moisture content

\section{Conclusions}

The sorption isotherms of Warionia saharae leaves were determined with the static gravimetric method .Peleg and Gab models were found the most suitable to describe the relationship between equilibrium moisture content and water activity .the isosteric heat of sorption were using the Clausius-Clapeyron equation. The heats of sorption increased with decreasing moisture content. The drying rate was characterized by the absence of the period (0) and (1) which corresponds to the period of drying at increasing rate and at a constant rate respectively and the presence of the single period of the decreasing rate. That have been observed in the drying of different fruits and vegetables. The modelling of kinetics curves will be established in our next paper. 
Modeling the Water Sorption Isotherms of Warionia Saharaeand determination of sorption heats and drying kinetics

\section{References}

[1] Bonnet and Maurry, P. Etude sur le Warionia Saharae . Benth \& coss.Assoc. Fr. Avanc. Sc. Congrès de Paris 1889.

[2] Bellakhdar,J. La pharmacopée marocaine traditionnelle médecine arabe ancienne et savoir populaire. ibis press 1997,208.

[3] Bellakhdar , J.; Baayaoui ,A.; Kazdari ,A ; Marechal , J. Al Biruniya 1986, 3, 7-50.

[4] Hilmi ,F.; Sticher ,O .; Heilmann . Nat Prod 2002 , 65, 523-526.

[5] Hilmi ,F.; Sticher, O .; Heilmann .Planta Med 2003, 69 , 462-464.

[6] Hilmi, F.; Gertsch, J.;Bremner ,P.;Valovic ,S.;Heinrich ,M.; Sticher ,O .; Heilmann.Bioorg Med Chem 2003, 11, 3659-3663.

[7] Essaqui , A. ; Elamrani, A. ;Benaissa ,M. ; Rodrigues ,A.I. ;Yoongho, L. Essent OilBearing Plants 2004 , 7(3), 250-254.

[8] Yurtsever, S .Mathematical modeling and evaluation of microwave drying kinetics of mint(menthe spicata L). Applied science 2005, 5(7),1266-1274.

[9] Mujumdar, A.S.2.Handbook of Industrial drying, Taylor and Francis group, U.K.2007

[10] Paulo , C. C.; Evandro d. C. M.; Rocinely, P. d. .Mathematical modeling of the drying kinetics of the leaves of lemon grass (Cymbopogon citratus Stapf) and its effects on quality. IDESIA 2014,32, (4) 43-56 .

[11] Mc Laughlin, C. P.; MAGEE, T. R. A. The determination of sorption isotherm and the isosteric heats of sorption for potatoes. Food Engineering, v 1998. 35(3), 267-280.

[12] Yu, L., Mazza ; Jayas ,D.S. Moisture sorption of characteristics of freeze-dried, osmo-dried and osmo-air dried cherries. Transactions of the ASAE 1999, 42(1): 141147.

[13] Delgado, A. E.; Sun, D.-W. Desorption isotherms for cooked and cured beef and pork .Food Engineering 2002B, 51, 163-170.

[14] Jayendra Kumar, A.; Singh, R.R.B.; Patil, G.R.; Patel, A.A. Effect of temperature on moisture desorption isotherms of kheer 2005, LWT, 38, 303-310.

[15] Wang, N.; Brennan, J. G. Moisture sorption isotherm characteristics of potatoes at four temperatures. Food Engineering 1991, 14, 269-282.

[16] Kouhila, M. Etude expérimentale et théorique de cinétiques des séchages convectifs partiellement solaires des plantes médicinales et aromatiques (Menthe, Verveine, Sauge et Eucalyptus) de la région de Marrakech (PhD Thesis) Universite Cadi Ayyad de Marrakech, Morocco 2001, 170.

[17] Al Hodali, R. Numerical simulation of an agricultural foodstuffs drying unit using solar energy and adsorption process (PhD Thesis). Université Libre de Bruxelles. Belgium 1997. 